\title{
Measuring total plasma amino acid concentrations as a test of exocrine pancreatic function
}

\author{
A M Allen, P S Oates
}

\begin{abstract}
Endogenous and exogenous stimulation of the pancreas was studied to determine whether changes in protein output could be linked to decreased total plasma amino acid concentrations. In fasted rats, diversion of pancreatic juice resulted in a transient increase in protein output and a linked fall in total plasma amino acid. In fed animals, however, diversion of juice did not result in any change in protein output or total plasma amino acid concentrations, although protein output was two-fold greater than in fasted animals. Similarly, after atropine treatment, diversion of juice failed to result in any change in protein output or total plasma amino acid in either fed or fasted animals. Stimulation of the gland with increasing doses of cholecystokinin ranging from 1.25 to 10.00 Crick Harper Raper Units, resulted in dose response increases in protein output and corresponding dose response falls in total plasma amino acid concentrations. Maximum decrease in total plasma amino acid concentrations was seen at $50 \%$ from the baseline with 5.00 Crick Harper Raper Units of cholecystokinin. These results show that with exogenous and endogenous stimulation in fasted animals, a highly significant, inverse relationship exists between protein output and total plasma amino acid. This relationship is the basis for a reliable, non-invasive test of pancreatic function that allows free mobility, although a period of fasting is required in order to increase the sensitivity of the test.
\end{abstract}

Within the array of procedures available for testing exocrine pancreatic function, the most accurate (75-90\% diagnostic accuracy) involves intubation and therefore is substantially invasive, time consuming, expensive, and uncomfortable for the patient. ${ }^{12}$ Other less invasive tests have considerably lower diagnostic accuracy. ${ }^{12}$

A number of reports recently have suggested that exocrine pancreatic function can be accurately assessed with a diagnostic sensitivity of between $87-90 \%$ by using changes in total plasma amino acids after infusion of cholecystokinin or the cholecystokinin analogue, caerulein. ${ }^{3-7}$ It has been shown that in healthy man, a constant infusion of a single dose of cholecystokinin plus secretin results in a maximum fall in total plasma amino acid of $31 \%,{ }^{3}$ while the same dose of caerulein plus secretin decreased total plasma amino acid maximally by 23.7 and $24 \cdot 7 \%$, respectively. ${ }^{46}$ Conversely, infusion of cholecystokinin 8 alone failed to change total plasma amino acid concentrations. ${ }^{8}$

This test is based on the hypothesis that in its active phase the pancreas is the most active user of amino acids in the body. Thus, when stimulated with either cholecystokinin or caerulein, protein discharge is followed by markedly increased protein synthesis and a concomitant uptake of amino acids from the plasma is expected. Protein synthesis proceeds, deriving amino acids from the plasma until the effects of the stimulation are complete.

It was in only one of these studies that Domschke and coworkers ${ }^{3}$ correlated an increase in duodenal chymotrypsin activity with maximal decrease in total plasma amino acid concentrations $\mathbf{4 5}$ minutes after stimulation. In order to extend this hypothesis, changes in total plasma amino acid were measured after stimulation with a wide range of cholecystokinin concentrations, to determine whether differing pancreatic secretory capacities could also be linked in time and extent with corresponding changes in total plasma amino acid. In the present study a relatively impure preparation of cholecystokinin was selected, because changes in total plasma amino acid concentrations after pancreatic secretion appear to be enhanced by other pancreatic secretatogogues in addition to cholecystokinin. ${ }^{3-7}$ Second, endogenous stimulation of the gland was explored to see whether this treatment could also cause changes in total plasma amino acid.

\section{Methods}

\section{ANIMALS}

Twenty four male, Albino Wistar rats inbred since 1960 were obtained from the State Animal Resources Centre (Murdoch, WA). The animals were housed in hanging stock cages, with eight animals per cage in a room with a 12 hour light/ dark cycle kept at a temperature of $21-23^{\circ} \mathrm{C}$. Tap water was freely available and the animals were fed a standard laboratory chow, the composition of which has been reported previously. ${ }^{9}$ Food was either withheld for 24 hours or made available up to the time of testing. At the time of testing the animals weighed about $475 \mathrm{~g}$.

\section{TREATMENT GROUPS}

Total plasma amino acid concentrations and pancreatic protein output were estimated in surgically treated animals under the following five conditions. The number of animals used in each test is also shown in parenthesis: $i$ fasted (four); ii fasted with atropine, (four). Atropine was given intravenously as a bolus dose of $100 \mu \mathrm{g} / \mathrm{kg}, 30$ minutes before collection and at hourly intervals throughout the study. This dose of atropine has been shown to inhibit the hyper-
Bepartment of Hum Community Health, Bentley, W Australia 
secretory response to pancreatic juice diversion $^{10-12}$; iii fed (four); iv fed with atropine (four); $\mathrm{v}$ fasted + stimulation with a low dose range of $0.31,0.62$ and 1.25 Crick Harper Raper Units of cholecystokinin (four), plus another four rats received 2.50, 5.00 and 10.00 Crick Harper Raper Units as a high dose range. Cholecystokinin was injected as described previously. ${ }^{13}$ Two ampoules containing a total of $200 \mathrm{IU}$ of cholecystokinin purchased from Sigma (P2000) was used to stimulate pancreatic secretions.

\section{SURGICAL PROCEDURE}

The animals were anaesthetised intraperitoneally with urethane $(25 \% \mathrm{w} / \mathrm{v})$ made up in normal saline at a dose of $1.25 \mathrm{~g} / \mathrm{kg}$ body weight. Seventy five per cent of the dose was given initially with the remainder given 30 minutes later. It has been shown that pancreatic secretion varies during the first three hours after anaesthesia with urethane, therefore sampling of pancreatic juice did not start until three hours after the first dose of urethane. ${ }^{14}$ Body temperature was maintained at $37^{\circ} \mathrm{C}$ by means of a heating pad and monitored by a rectal thermometer.

Three hours after anaesthesia the external jugular vein was cannulated using SP 31 tubing $(0.5 \mathrm{~mm}$ id and $0.8 \mathrm{~mm}$ od, purchased from Dural Plastic and Engineering, Dural, NSW) for blood sampling, and when performed for injections of cholecystokinin and atropine. The cannula was inserted a distance of between 1.5 to $2.0 \mathrm{~cm}$ and then approximately $100 \mu \mathrm{l}$ of heparinised $(100 \mathrm{U} / \mathrm{ml})$ saline was injected. After checking patency of the cannula by withdrawing blood the wound was covered with saline soaked gauze.

The abdominal wall was opened by a longitudinal incision and the duodenal segment of the pancreas exteriorised. The pancreatic duct at its point of entry into the duodenum was then identified and cannulated with SP 10 polyethylene tubing $(0.28 \mathrm{~mm}$ id and $0.61 \mathrm{~mm}$ od, Dural Plastics). The cannula was inserted a distance of $3 \mathrm{~mm}$ and secured by ligatures and a drop of Superglue ${ }^{\circledR}$. The bile duct was ligated distal to the hilum of the liver and at a point proximal to entry into the pancreas. The pylorus was ligated in fasted animals and left open in animals fed up to surgery.

\section{COLLECTION AND PROCESSING OF SAMPLES}

\section{Blood samples}

Immediately after cannulation of the pancreatic duct, $200 \mu \mathrm{l}$ blood was removed from the jugular cannula to begin the study and to establish baseline levels for total plasma amino acid, and then at 20 minute intervals to match collections of pancreatic secretions. The blood was expelled gently into a $300 \mu \mathrm{l}$ microfuge tube, containing $25 \mu \mathrm{l}$ of heparinised saline $(100 \mathrm{U} / \mathrm{ml})$ and mixed. The samples were placed on ice and processed collectively at the end of the collection period. It has been shown previously ${ }^{15}$ that total plasma amino acid concentrations can be affected when allowed to settle before processing, however, experiments in this study showed that there was no significant difference in total plasma amino acid concentrations in a series of samples processed immediately after collection compared with the same samples processed three hours later. The samples were centrifuged at $3000 \mathrm{rpm}$ for 15 minutes and $100 \mu \mathrm{l}$ plasma removed to other microfuge tubes and deproteinised with $25 \mu \mathrm{l} 10 \%$ sulphosalicyclic acid for one hour on ice. $^{3}$ The samples were then centrifuged for 20 minutes at $5000 \mathrm{rpm}$ followed by the removal of $50 \mu \mathrm{l}$ deproteinised solution for assay of total amino acid content by reacting the amino group with ninhydrin according to the method of Yemm and Cocking. ${ }^{17}$ Control experiments showed that after deproteinisation with sulphosalicylic acid the protein content of the supernatant as assessed by the method of Schacterle and Pollack ${ }^{18}$ was below detection. Any reaction with ninhydrin therefore was because of the presence of free amino acids. Recovery of amino acids from the plasma before and after deproteinisation was greater than $95 \%$. Total plasma amino acid concentrations were compared with a standard curve constructed using tyrosine. Under these conditions of collection and determination, total plasma amino acid concentrations in this study are similar to those reported previously. ${ }^{19} 20$

\section{Pancreatic juice}

Once the blood sample had been taken, either a precalibrated silicone tube or a preweighed polyethylene tube was attached to the cannula and a clock started. Collection of pancreatic juice were at 20 minute intervals and extended up to 180 minutes. At the end of each collection period the reservoir was removed and the volume calculated as described previously. "The samples were made up to $3 \mathrm{ml}$ with saline and mixed thoroughly. The total protein content of the juice was estimated by the method of Schacterle and Pollack. ${ }^{18}$

\section{ANIMAL WELFARE}

The experimental design described above was approved by the Curtin University Animal Welfare and Ethics Committee.

\section{STATISTICAL ANALYSIS}

Data are expressed as the mean (SD). When comparing changes from the baseline for protein output and total plasma amino acid after stimulation with cholecystokinin and diversion of pancreatic juice, the data were analysed by the Student's $t$ test for paired samples. When comparing protein output and total plasma amino acid between fed and fasted, atropine and nonatropine treated rats, the data were assessed by the Student's $t$ test for unpaired samples. Significance is considered to be $\mathrm{p}<0 \cdot 05$.

\section{Results}

EXOGENOUS STIMULATION OF THE PANCREAS At doses of cholecystokinin that stimulate the pancreas, protein output was highest at the end 
Figure 1: Pancreatic protein output $(1 A)$ and plasma amino acid levels (IB) per 20 minute interval, after stimulation with bolus injections of cholecystokinin (CCK) ranging from 0.31 to 10.00 Crick Harper Raper Units (CHRU). Arrows indicate injection of cholecystokinin. Animals were fasted for 24 hours before surgery. Results are mean $(S D)$ of four rats per group. $\star$ indicates significantly different from baseline.
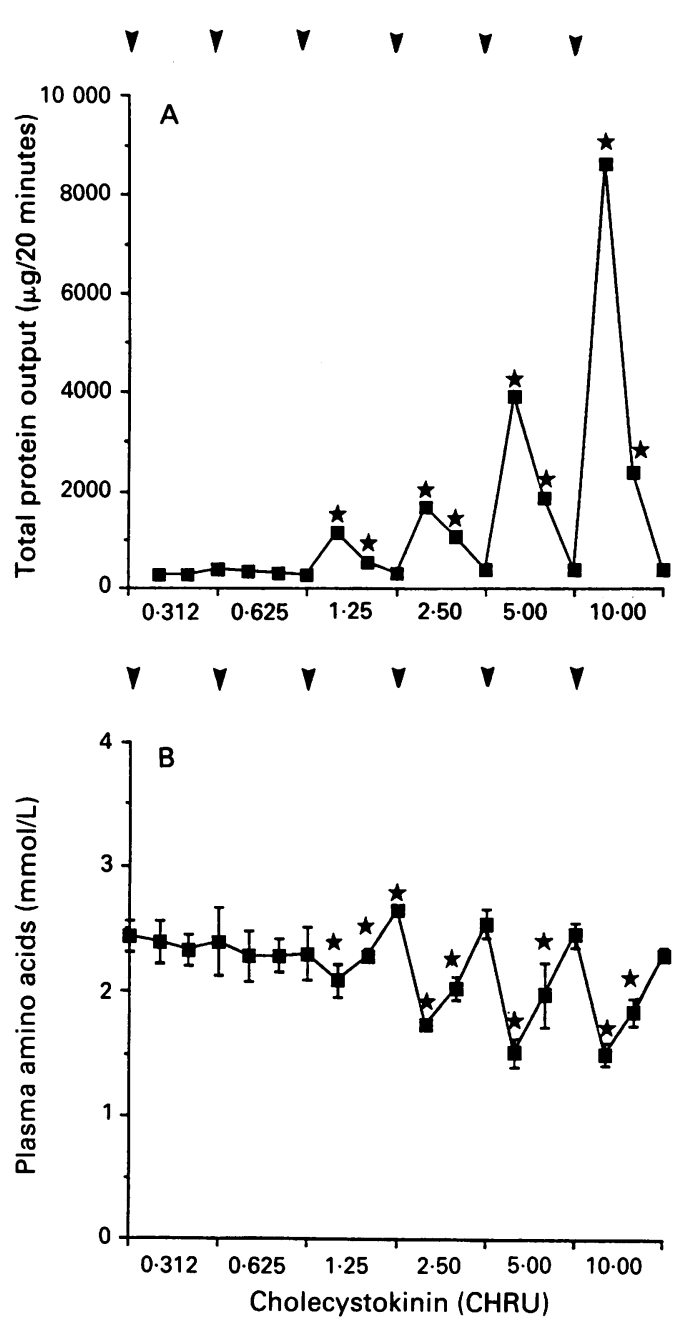

of the first 20 minute period and then fell to return to basal levels by 60 minutes (Fig la). As stimulated protein output and total plasma amino acid concentrations returned to basal concentrations by 60 minutes, the two dose ranges were combined to establish a dose response relationship from 0.31 to 10.00 Crick Harper Raper Units of cholecystokinin plotted against changes in protein output/20 minute interval (Fig la) or total plasma amino acid/20 minute interval (Fig lb).

Stimulation from 1.25 Crick Harper Raper Units of cholecystokinin resulted in stimulated protein output that was associated with corresponding falls in total plasma amino acid. Maximal decrease was seen at 50\% from basal levels at a dose of 5.00 Crick Harper Raper Units of cholecystokinin (Figs la, b). When 10.00 Crick Harper Raper Units of cholecystokinin was given, protein output significantly increased above the 5.00 Crick Harper Raper Units response, however, at this dose it took longer for total plasma amino acid to return to baseline than with the previous dose (Fig 1b). A linear regression calculated for stimulated protein output against total plasma amino acid over the entire dose range used $(0.31$ to 10.00 Crick Harper Raper Units) resulted in a highly significant, inverse relationship with a correlation coefficient of -0.804 (Fig 2), although as a result of the maximal decrease in total plasma amino acid at 5.00 Crick Harper Raper Units the correlation coefficient could be improved to $-0 \cdot 890$ with the

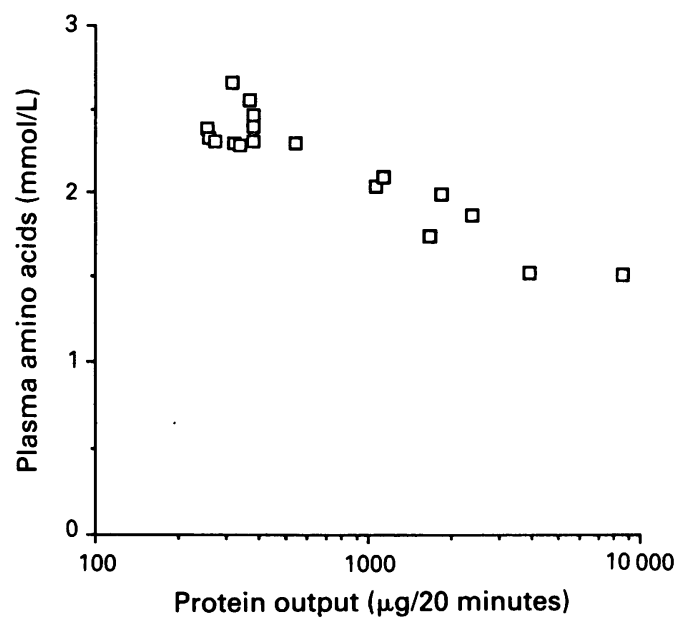

Figure 2: Linear regression constructed for stimulated protein output plotted against total plasma amino acid concentrations over the dose range of 0.31 to 10.00 Crick Harper Raper Units of cholecystokinin. The animals were fasted for 24 hours before surgery.

omission of data at 10.00 Crick Harper Raper Units. The equation to this latter linear regression was $y=-2 \cdot 692 \times 10^{-4}(x)+2 \cdot 459$.

ENDOGENOUS STIMULATION OF THE PANCREAS After diversion of bile pancreatic juice in fasted, non-atropine treated animals, a hypersecretory response was seen peaking at $\mathbf{4 0}$ minutes and
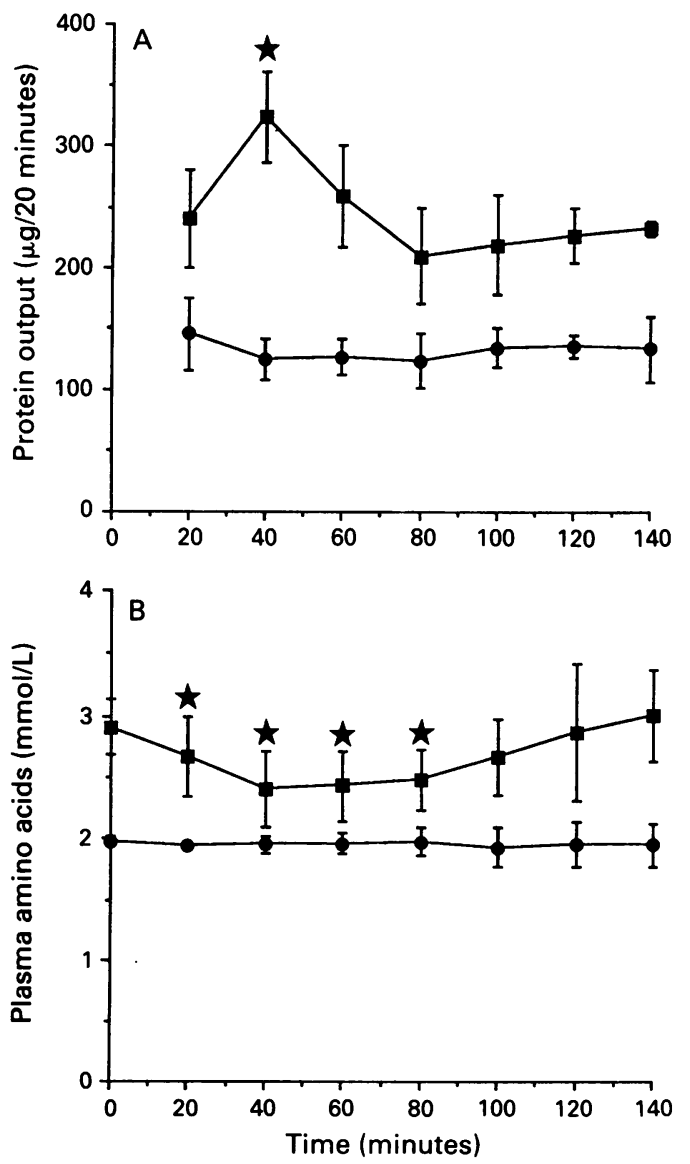

Figure 3: Protein output (3A) and total plasma amino acid concentrations $(3 B)$ after diversion of bile pancreatic juice from the duodenum in non-atropine ( $\mathbf{a})$ and atropine (O) treated animals. The animals were fasted for 24 hours before surgery. Results are the mean $(S D)$. $\star$ indicates significantly different from baseline. 


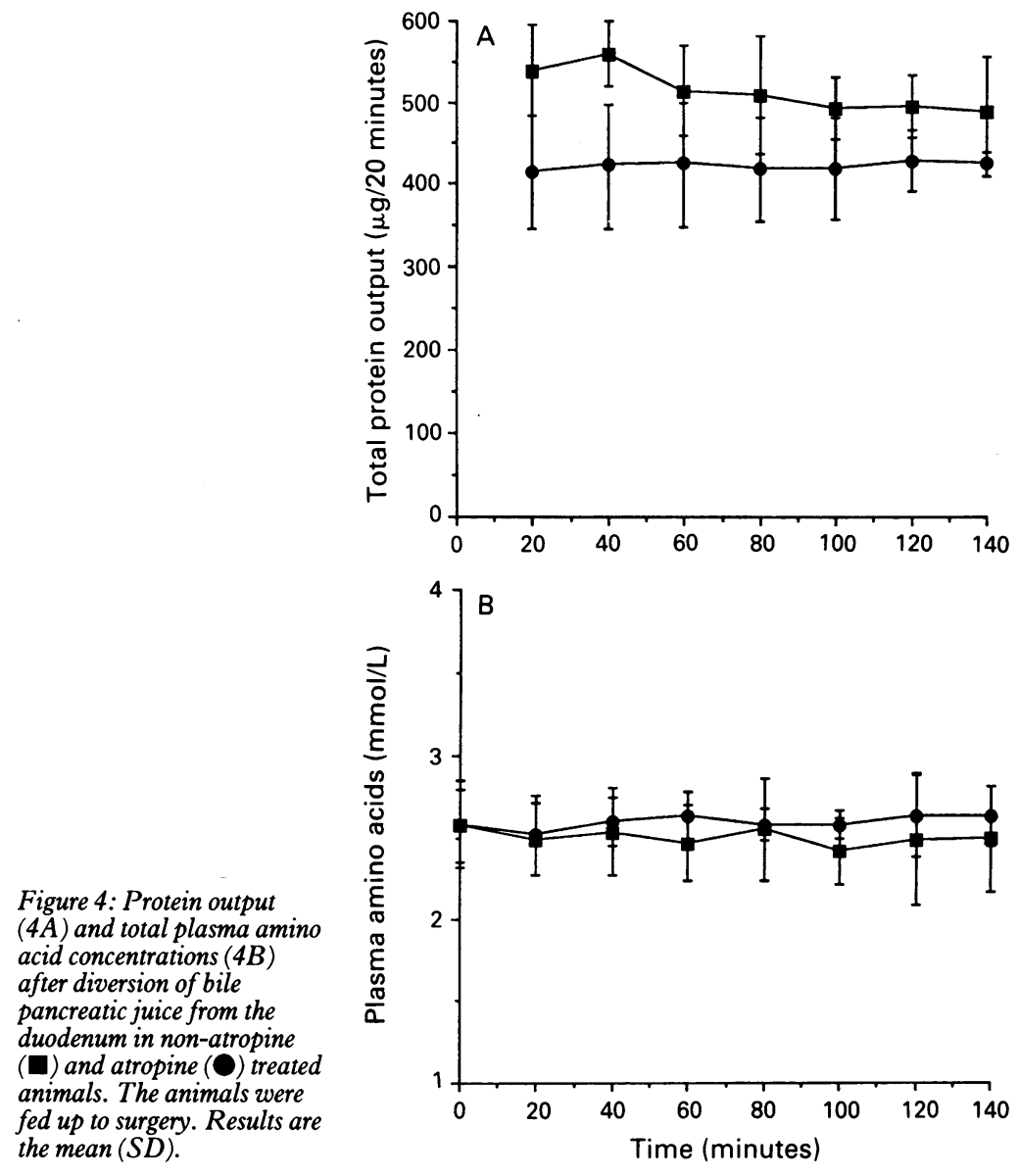

returning to baseline levels by 60 minutes (Fig 3a). At the time of peak hypersecretion, total plasma amino acid concentrations were significantly lower than baseline concentrations but returned to this level at 100 minutes (Fig $3 b$ ). In fasted, atropine treated rats, basal secretions remained unchanged throughout the study and similarly there was no change in total plasma amino acid concentrations at any interval studied (Figs 3a, b).

After the hypersecretory response, protein output and total plasma amino acid were lower by $40 \%$ and $27 \%$, respectively in atropine compared with non-atropine treated animals (Figs 3a, b).

When the above experiment was repeated in fed animals, no hypersecretory response was seen, nor was there any change from baseline in total plasma amino acid (Figs 4a, b). Also in fed, atropine treated rats, pancreatic secretions failed to change protein output and total plasma amino acid from baseline values (Figs $4 a, b$ ). Except at 40 minutes after diversion in non-atropine, fed rats, protein output was not significantly different compared with atropine treated animals (Fig 4a). No difference in total plasma amino acid existed between the two groups. In the fed state, protein output was significantly greater by between 200 $250 \%$ than in their respective fasted states (Figs $3 a, 4 a)$.

\section{Discussion}

In this study, changes in total plasma amino acid and pancreatic protein output were measured after endogenous and exogenous stimulation to determine whether changes in total plasma amino acid could be correlated with protein output, and therefore more extensively test this hypothesis of pancreatic function. In previous studies where pancreatic function was assessed by changes in total plasma amino acid,,$^{3-7}$ the gland was stimulated by a constant infusion of caerulein or cholecystokinin and the changes in total plasma amino acid estimated. It was concluded that the change in total plasma amino acid associated with this stimulation was the result of increased uptake of amino acids by the pancreas, although it was only in one of these studies, using one dose of cholecystokinin, at one time point that duodenal chymotrypsin activity was compared with changes in total plasma amino acid. In the present study this relationship was tested by stimulating the gland with six different doses of cholecystokinin, covering a 32-fold range of cholecystokinin concentrations, and at three time points per dose to determine whether total plasma amino acid accurately mirrors the change in protein output. The results show that over the dose range of cholecystokinin used there was a highly significant inverse relationship between protein output and total plasma amino acid, a finding which provides further support for the hypothesis that total plasma amino acids are a valid measure of pancreatic function. Furthermore, the results show that total plasma amino acid decrease maximally by $50 \%$ despite increased protein output from the pancreas with 10.00 Crick Harper Raper Units of cholecystokinin. The inability to decrease total plasma amino acid below $50 \%$ despite increased protein output with 10.00 Crick Harper Raper Units, probably reflects saturation of the mechanism involved in the uptake of amino acids and protein synthesis. In support of this, the finding that at 10.00 Crick Harper Raper Units of cholecystokinin, total plasma amino acid concentrations took longer to return to baseline values than with 5.00 Crick Harper Raper Units.

In order to determine whether changes in total plasma amino acid can be seen during endogenous stimulation of the gland, pancreatic juice was diverted from the duodenum in fasted rats. This treatment resulted in a transient increase in protein output which was associated with a significant fall in total plasma amino acid. This finding indicates that endogenous stimulation does decrease total plasma amino acid, and furthermore, supports the view of the specific uptake of amino acids by the pancreas, because atropine abolished the hypersecretory response and total plasma amino acid did not change. In this experimental design it was thought that diversion of pancreatic juice would closely mimic the intestinal phase of pancreatic secretion. In fact, the protein output in rats fed up to surgery was $1 \cdot 5$-fold greater than that seen at peak protein output during diversion of pancreatic juice in the fasted state. This suggests that changes in total plasma amino acid can be detected with very low levels of pancreatic stimulation indeed. It seems, however, that in order to detect changes in total plasma amino acid as a result of endogenous stimulation, the animal needs to be fasted before the study. A possible explanation to account for this lack of 
sensitivity in the fed state is that uptake of amino acids by the pancreas is balanced by absorption from the gut.

If this endogenous test proves as sensitive in man as it appears to be in the rat, then the study of natural and synthetic trypsin inhibitors on pancreatic function in the human pancreas would be possible. The testing of trypsin inhibitors under these circumstances would rely on the dietary inhibitor binding strongly with the proteolytic enzymes and passing through the digestive tract largely undigested and unabsorbed.

It should be noted that the preparation of cholecystokinin used in the present report was purchased from Sigma and as stated by these manufacturers was contaminared with secretin. In previous studies involving the human, either Kabi cholecystokinin or caerulein were used in combination with secretin and resulted in maximal decreases in total plasma amino acid of $31 \%{ }^{3}$ and $24 \%,^{+7}$ respectively. When cholecystokinin $^{8}$ was given alone no change in total plasma amino acid concentrations were observed. ${ }^{8}$ If the rat and human pancreas respond to these preparations of cholecystokinin similarly, then it appears that the decrease in total plasma amino acid is enhanced by a background infusion of secretin and therefore, this possibility should be considered in these tests of pancreatic function.

In conclusion, it is suggested that the measure of total plasma amino acid as a test of exocrine pancreatic function over a wide range of stimulated secretions is valid. It is recommended that a period of fasting precede the test in order to increase the sensitivity of the technique. The use of bolus injections of a relatively impure preparation of cholecystokinin results in a highly significant inverse relationship between cholecystokinin and total plasma amino acid that is complete within 60 minutes. This has advantages over continuous infusion, because it allows mobility during the test, thus obviating the need for restraint and infusion equipment. This experimental design may be relevant in human studies.

1 Lankisch PG. Tubeless pancreatic function tests. Hepatogastroenteroloyy 1981; 28: 333-8.

DiMagno EP, Clain JE. Chronic pancreatitis. In: Go VLW, et al eds. The exocrine pancreas: biology, pathobiology, and diseases, New York: Raven Press, 1986: 562-75.

3 Domschke S, Heptner G, Kolb S, Sailer D, Schneider MU, Domschke W. Decrease in plasma amino acid level after secretin and pancreozymin as an indicator of exocrine pancreatic function. Gastroenterology 1986; 90: 1031-8.

4 Gullo L, Pezzilli R, Barbara L. Effect of somatostatin on pancreatic amino acid uptake. [Abstract]. Pancreas 1988; 3. A599.

5 Gullo L, Pezzelli R, Ventrucci M. Cerulein-induced plasma amino acid decrease: A simple, sensitive, and specific test of

6 ciullo L, Pezzilli R, Barbara L. Effect of somatostatin on plasma amino acid uptake by human pancreas. Gastroplasma amino acid uptake

7 Gullo L, Pezzilli K, Ventrucci M, Barbara L. Caerulein induced plasma amino acids decrease - A simple sensitive, and specific test of pancreatic function. Gut 1990; 31: 926-9.

8 Maringhini A, Jones JD, Nelson DK, DiMagno EP. Is plasma amino acid concentration (AA) after CCK-OP an accurate ineasurement of exocrine pancreatic function. [Abstract]. Pancreas 1990; 5: A721.

9 Crass RA, Oates PS, Morgan RGH. The effect of fasting on enzyme levels in the enlarged and involuting rat pancreas. Br F Nutr 1987; 58: 427-36.

10 Fushiki T, Fukuoka S, Iwai K. Stimulation of rat pancreatic enzyme secretion by diet components. Agric Biol Chem 1984; 48: $1867-74$.

11 Fukuoka S, Tsujikawa M, Fushiki T, Iwai K. Stimulation of pancreatic enzyme secretion by a peptide purified from rat bile-pancreatic juice. F Nutr 1986; 116: 1540-6.

2 Fushiki T, Fukuoka S, Iwai K. Stimulatory effect of an endogenous peptide in rat pancreatic juice on pancreatic enzyme secretion in the presence of atropine: evidence for different mode of action of stimulation from exogenous trypsin inhibitors. Biochem Biophys Res Comm 1984; 118: $532-7$.

13 Oates PS, Morgan RGH. Pancreatic response of anaesthetized and conscious rats to bolus injections of cholecystokininpancreozymin. Aust f Biol Sci 1981; 34: 283-93.

14 Love JW. A method for the assay of secretin using rats. Of Exp Physiol 1957; 42: 279-84.

15 Perry TL, Hansen S. Technicai pitfalls leading to errors in the quantitation of plasma amino acids. Clin Chim Acta 1969; 25: $53-9$

16 Armstrong $M D$, Stave V. A study of plasma free amino acid levels 1 . Study of factors affecting validity of amino acid analysis. Metabolism 1973; 22: 549-60.

7 Yemm EM, Cocking EC. The determination of amino acids with ninhydrin. Analyst 1955; 80: 209-16.

18 Schacterle GR, Pollack RL. A simplified method for the quantitative assay of small amounts of protein in biologic material. Anal Biochem 1973; 5i:654-5.

19 Miller LL. The role of the liver and the non-hepatic tissues in the regulation of free amino acid levels in the blood. Amino acid pouis. In: Holder JT, ed. Amsterdam: Elsevier, 1962.

20 Scharff $R$, Wool IG. Concentration of amino acids in rat muscle and plasma. Nature (Lond) 1964; 202: 603-4. 